\title{
Navigating the Dark Side of Digital Space
}

\section{Study Case on the Phenomenon of Digital Fear of Missing Out (Fomo) in Twitter of K-Pop Fans in Bandar Lampung}

\author{
Cindyta Adevia Ananda ${ }^{1,}$ Andi Windah ${ }^{2 *}$ \\ ${ }^{1,2}$ Communication Department, Universitas Lampung \\ *Corresponding author. Email: andiwindah@gmail.com
}

\begin{abstract}
Korean culture has continuously entered Indonesia since the 2000s. K-Pop fans (Korean music fans are called) are increasingly rampant in Indonesia and closely related to the stereotype of fanaticism. Teenagers are categorized as the biggest consumers of K-Pop commodities. This is made easier by the development of existing media and technology, for example through social media such as Twitter. The digital space offered by Twitter provides an opportunity for Indonesian K-Pop fans to access various entertainment related to Korea. Digital space with high accessibility and fast interactivity has the opportunity to create the phenomenon of fear of missing out (FoMO), the desire to continue to connect with what other people are doing so that it causes excessive fear or worry of missing out, for K-Pop fans. This study aims to determine the effect of digital space on the Twitter social media platform on K-Pop fanaticism, especially in discussing the phenomenon of FoMO. The results show that the digital space, especially Twitter, has a low influence on the FoMO phenomenon. The magnitude of the influence of Twitter is $34.8 \%$, it can be concluded that the influence of digital space on K-Pop fanaticism belongs to the moderate level of correlation.
\end{abstract}

Keywords: Digital space, Twitter, FOMO, K-Pop

\section{INTRODUCTION}

K-Pop which is an acronym for Korean Pop or Korean Popular Music is a type of popular music from the country of ginseng, South Korea. This K-Pop invasion is often referred to as hallyu or the Korean wave. K-Pop itself grows and develops to form a subculture that has successfully spread its wings throughout the world. In its development, K-Pop is more centered on idol groups than solo singers. As a group, each idol group portrays the image they build for the group, but what makes idol groups more attractive is the diversity that exists within the group.

Each member has their own charm, both in dancing, singing, performance, and others. According to Sella Ayu Pertiwi's [1] research revealed that K-Pop fans collect a lot of their idol's knick-knacks such as posters, albums, magazines, photo-books, and various other productions. K-Pop fans will also make an effort to watch their idol's concerts and even keep a snippet of the idol's concert ticket as a token for them. The tendency of K-Pop fans to like their idols excessively can make themselves into fanatical fans.

Hometsberger, et al [2] define fanaticism as an extraordinary devotion to an object. The dedication consists of passion, intimacy and extraordinary dedication that reaches above average levels. From research conducted by Eliani, Yuniardi, \& Masturah [3], a high level of fanaticism encourages social media behavior of K-Pop idol supporters such as producing, consuming, and discussing information with other fans. So if you don't do that, you will always feel unsatisfied as a fan.

K-Pop fans have a negative stereotype that is excessive fanaticism. These stereotypes identify K-Pop fans who are willing to do anything to prove their love for the idol. Frequently, they are referred to as people who have mental disorders. Jenkins [3] mentions that fan is short for fanatic. In his explanation, the term changes to a negative connotation of enthusiastic madness. The term changed again to over-enthusiasm and misguided. There is also a stereotype that fans are 
emotionally unstable, unable to adjust to the social world, and dangerously out of tune with real life. Therefore, die-hard fans tend to prefer life in cyberspace which is considered more fun than real life. According to Nuralin [4], Magetian states that the proximity of fans to media content can lead to fanaticism in these fans. Many fanatical fans experience anxiety if they don't open their social media accounts for just one day for fear of missing the latest or real-time information from their idols.

So far, Twitter has become the social media most frequently used by K-Pop fans in finding the most upto-date information because of its real-time nature. According to the Korea Herald, there were 6.1 billion tweets talking about K-Pop throughout 2019 and Indonesia was in third place (http://m.koreaherald.com/amp/view.php?u=202001140 00546). In addition, there are many large fan-bases between fandoms from different countries that are active 24 hours a day on Twitter. The official accounts of favorite idol groups as well as the official personal accounts of their idols are also available on Twitter. With the hours spent by fans using Twitter to access information about K-Pop, interacting with idols and fandom friends, looking for the latest photos of the idol from fan site, and doing not rule out the possibility that the growing anxiety and feelings of fear of being left behind occurs in a K-Pop fan [5].

The fear of losing precious moments is called FoMO (Fear of Missing Out) which is characterized by the desire of an individual to stay connected and know what other people are doing through social networks or the internet. One of the characteristics of the Fear of Missing Out phenomenon is the individual's fear of missing out on information because they feel they are not up to date. An individual who experiences FoMO symptoms will continue to be addicted in accessing the internet and social media [6]. In this case, FoMO's behavior is then assumed to be influenced by fanaticism in a K-Pop fan. The higher the level of fanaticism of a fan, the more often those fans will look for information on Twitter and experience a feeling of anxiety if they do not open Twitter regularly because of the lack of information. This condition raised the researchers curiosity about the influence of fanaticism of Indonesian K-Pop fans on Fear of Missing Out behavior on Twitter.

\section{LITERATURE REVIEW}

\subsection{Fanaticism and K-Pop Fans}

According to Fuschillo [7], fanaticism is a strong emotional commitment to a value package and occurs as an individual and or group process. These values are very different from the dominant culture and produce different kinds of things that seem impossible to coexist with other people's values, so that fanaticism breeds extremism, fundamentalism, and terrorism such as cult activities and others. Milgram defines a fanatic as someone who has extreme beliefs, feelings, and actions [8]. Milgram states that fanatics use belief systems as a crutch that prevents them from falling in self-esteem. Thorne \& Bruner [9] defines fanaticism as the intensity level of fan involvement that varies from low intensity to the highest intensity, namely dilettante, dedicated, dedicated, and dysfunctional. In this context, Thorne and Bruner view fanaticism as a neutral term even though it has a negative connotation.

Fanaticism can also appear in the world of sports. Loyal supporters of sports, athletes, sports clubs, games, musicians, bands, actors, or other similar attractions are usually called fans. Fans can be loyal and loyal without being fanatical but a tendency towards fanaticism is sometimes found specifically among fans [10]. In this context, fanatics then have a close relationship with fans. Fans are stereotyped as emotionally unstable, unable to adjust to the social world, and out of tune with real life. Another stereotype of fans is a group of people who are obsessed with something. According to Jenson [11], fandom is usually associated with deviance while fans are closely related to fanaticism. There are two types of fan pathology mentioned by Jenson, namely individuals who have an obsession (usually maledominated) and hysterical associations (usually femaledominated).

K-Pop has become a form of pop culture that is spread dynamically in the global pop market through social distribution networks. Korean popular culture, commonly known as Hallyu or the Korean Wave, has been recognized and widely accepted since the early 2000s by Asians and some global audiences. According to Jung \& Shim [12], K-Pop is widely circulated through new media platforms such as fan blogs, usergenerated content (UGC) websites, peer-to-peer file sharing sites, and social networking services (SNS). Otmagzin \& Lyan [13] mentions that since around 2010, Korean popular music, or K-Pop has penetrated into the Middle East through a group of fans who are interested in Korean popular culture. Supported by the power of social media as a means of accessing and consuming cultural content, Korean films, and television series, recently K-Pop has carved a gap between a growing group of consumers, especially young women. Through virtual fandoms, fans share information, pictures, video clips, and gossip related to K-Pop. The number of Hallyu fans globally was 89.19 million as of December 2018 as reported by The Korea Foundation. This number increased by 22\% from 2017 (73.12 million people). From 2016 to 2017, there was an increase in the number of Hallyu fans by 14 million people worldwide. The Korea Foundation then predicts that the number of fans will increase to 100 million people by 2020. As reported by The Jakarta Post (2019), that the 
significant increase in the number of fans is due to the increasing popularity of the BTS group.

\subsection{Information Searching Through Twitter}

Most modern individuals have been exposed to media. With the development of the era, the presence of the media is becoming more diverse and growing rapidly. The existence of new media makes it easier for individuals to communicate. Undeniably, the internet has influenced the way individuals communicate with other individuals. The internet provides a variety of information that has no limits and is able to meet human needs in communicating. Social media is a product of the emergence of new media. Through social media, users can search and share information and make friends with many people regardless of distance and time. Social media has functioned as a new medium of interaction that creates space for audiences to tell stories, share, and channel their ideas. As a result, audiences migrate virtual to find information or interact with other users in cyberspace.

According to Windah [14], new social media is an example of the development of media technology that has a big impact on today's life. Twitter is a social networking site for friends that free of charge, has provisions that can only attach messages of 140 characters called tweets, and allows its users to make many friends by registering themselves on the site. The spread of information on Twitter is very fast, where this site is able to display tens of thousands of tweets every second. The founders of the Twitter app are: Biz Stone, Evan Williams, and Jack Dorsey, in 2006.

\subsection{Understanding Fear of Missing Out as New Internet Addiction Phenomenon}

Fear of Missing Out or often referred to as FoMO comes from the Chinese language which means fear of losing others. Fear of Missing Out is a symptom of fear experienced by someone because they are left behind in information and unable to follow what is happening and what other people are doing on social media. This causes the audience to want to continue to connect with social media.

According to JWT Intelligence [15], there are several things that are included in the FoMO (fear of missing out) aspects, namely feelings of fear of losing the latest information on the internet, feelings of anxiety when not using the internet while other people use it, and feelings of insecurity. because left behind information scattered on the internet. There are several factors that influence the phenomenon of FoMO (Fear of Missing Out), the first is gender, personality traits, lack of face to face communication, and there is necessity factor.

\section{RESEARCH METHODOLOGY}

The approach used in this research is a quantitative approach with an explanatory survey method. The explanatory survey method serves to see the causal relationship between two or more variables. Questions in this method can be extended not only to establish the presence of causal relationships but also to question why these relationships exist. In this study, the independent variable is Fanaticism of K-Pop fans on Twitter. Meanwhile, the dependent variable in this study is the Fear of Missing Out Phenomenon.

The population in this study are K-Pop fans. According to data from The Korea Foundation, in 2018 there were around 89.19 million fans of Korean culture worldwide (2018). This figure is the result of an increase of 22 percent from the 2017 figure, which is around 73.12 million fans. The largest number of K-Pop fans is in Asia and Oceania (70.59 million members in 457 fan clubs). According to the report, there are around $1,218,000 \mathrm{~K}-\mathrm{Pop}$ fans in Indonesia, who were then act as the research population.

The sample taken for this research is K-Pop fans who use Twitter social media to access Kpop content. The research sample was taken from the number of Hallyu fans throughout Indonesia. However, due to huge amount of sample population, researchers took 100 respondents to represent the whole sample based on Slovin formula. The sample collection technique used in this study is a non-probability sampling technique. Researchers distributed questionnaires to K-Pop fanbase accounts on Twitter social media. The survey method is used to obtain data from a certain location that is natural (not artificial), but researchers use treatments when collecting data. The treatment is like distributing questionnaires, tests, and structured interviews. After that, the researcher used a Likert measurement scale in this study to measure the scale and determine the score. In addition, the researchers also conducted validity and reliability tests, and used data analysis techniques in the form of descriptive analysis, correlation analysis, and regression analysis. 


\section{RESULT AND DISCUSSION}

The distribution of the questionnaires in this study was carried out for 3 days, from September 10, 2020 to September 12, 2020. This questionnaire was distributed to $100 \mathrm{~K}-\mathrm{Pop}$ fans and selected according to the criteria the respondents access Twitter for K-Pop needs for 4-6 hours, which is $32 \%$. In second place are respondents who choose 10-12 hours with a total of 22 respondents. The least are respondents who choose more than 12 hours, namely 7 people $(7 \%)$. When viewed from the distribution of respondents' answers, it can be seen that

Table 1. Characteristics of Respondents Based on Length of Using Twitter to Access K-Pop Content

\begin{tabular}{|c|c|c|}
\hline Duration & Frequent (by person) & Percentage (\%) \\
\hline $1-3$ hours & 19 & 32 \\
\hline $4-6$ hours & 32 & 20 \\
\hline $7-9$ hours & 20 & 22 \\
\hline $10-12$ hours & 22 & 7 \\
\hline More than 12 hours & 7 & 100 \\
\hline Total & 100 & 19 \\
\hline
\end{tabular}

set out in this study, which are K-Pop fans who actively use Twitter. as a medium to access K-Pop content, residing in Indonesia and with an age range of 13-39 years. The age of the respondents in this study is important to see the penetration of Twitter in social media users and K-Pop fans. Based on the results of the questionnaire, it was concluded that the majority of respondents were aged 20-22 years. The largest number were respondents from the age group of 20 years and 22 years, with the same amount of $13 \%$. This number was followed by respondents aged 21 years with a total of $10 \%$. The least number are respondents from the age group of 28 years and 29 years with a number of $1 \%$ each.

Gender is an important aspect in discussing fandom studies, especially K-Pop. From the data, it can be concluded that most of the research respondents are women with a total of 97 people (97\%) and the remaining 3 people (3\%) are men. Then it can be said that K-Pop fans in Indonesia are still dominated by women. However, it can also be said that K-Pop is not only consumed by women but also consumed by men even though their number is still a minority.

The length of time used by respondents to access K-Pop content on Twitter is one of important data to answer the research questions. The data will later be linked to the behavior of fear of missing out. Table 1 shows the distribution of data on the length of time used by respondents in accessing K-Pop on Twitter. From the data presented in Table 11, it can be seen that most of there are respondents who answer 10 hours or even 21 hours accessing K-Pop content on Twitter in a day. From this data, it can be said that some respondents gave up their time to do other activities in order to access information related to their idols on Twitter.

The characteristics of fanaticism of K-Pop fans on Twitter in this study are seen using the characteristics of fanaticism, namely internal involvement, external involvement, desire to acquire, and interaction. While the phenomenon of fear of missing out is seen using indicators of fear, anxiety, and left out. After analyzing the characteristics of the respondents, the researchers conducted variable analysis to find the tendency of respondents' answers. From the analysis of the independent variables or characteristics of fanaticism on Twitter, it was found that in the dimension of internal involvement in the time sacrifice indicator, respondents were strongly agree that accessing Twitter is the most dominant activity they do every day. By making accessing Twitter as dominant activity to do, respondents continue to receive a lot of information and the latest content from their favorite idols to the point that they often stay up or sleep late at night. However, in terms of fund sacrifice, respondents did not agree with the claim that they are more willing to spend money to buy quotas so that they can continue to be connected to Twitter than for other purposes. They also disagree with the statement that they voluntarily buy paid content from their favorite idols. Then for the sacrifice of relationships in real life, respondents indicated that they 
still often interact with family and friends even though they are active in cyberspace.

Doing fandom activities seems to really make respondents feel pleasure, whether it's inner or mental pleasure, which in this derive pleasure indicator respondents agree that they will feel more enthusiastic when doing fandom activities on Twitter. On the external involvement dimension or external involvement carried out by fans in accessing content on Twitter, almost all respondents strongly agree with the demonstration indicator statement with some fandom activities they do on Twitter such as making tweets, uploading photos and videos related to idols, retweeting tweets, leaving comments or quoting tweets, using Twitter features such as likes and bookmarks, to being involved in voting for their idols' polls. This indicates that respondents use Twitter to the fullest as a forum to carry out their activities as K-Pop fans. In the dimension of desire to acquire, in the dimension of acquiring or the desire that K-Pop fans want to get, some of them do have a desire to be notified by idols, because wanting to be notified makes respondents willing to learn Korean. to make interaction easier.

For the characteristics of the fans interaction dimension in the social interaction indicator, respondents agree that they have this characteristic where respondents stated that they often interact with other K-Pop fans besides using twitter to search for content related to idols. This interaction is based on a discussion about their respective idols and fandom. While on the personal meaning indicator, respondents stated that they often try to interact with their idols. Meanwhile, for the dependent variable analysis of the fear dimension, respondents admitted that they were afraid of being left behind by the latest information from their favorite idol. For fear of being left behind, this causes respondents to always open and check Twitter at any time and time while they can.

In accordance to the Uses and Effect Theory, it was proven that respondents in this research chose Twitter as their mass media to fulfill their needs in doing fandom activities. It can be seen that the respondents strongly agree with the statement that Twitter is the most dominant social media they access every day with a maximum range of 4-12 hours.
If viewed from the point of view of the uses and effects theory, it can be concluded that the respondents of K-Pop fans have need for media that tends to be large so that it causes fanaticism. The level of need for access to media and content owned by fanatical fans is different from the level of need for casual fans. Fanatical fans will always feel dissatisfied with the content they receive and always want to get more content consumption. Fans who have the characteristics of fanaticism tend to have the behavior to be the first to know in everything related to their idols, making them have to check their twitter account every morning after waking up so they don't miss hot news.

Another unique discussion arise in this research is even though there is an influence between the variables $\mathrm{X}$ and $\mathrm{Y}$ according to the hypothesis test, the final result states that the influence of the level of fanaticism affecting the phenomenon of fear of missing out is considered quite low. The cause of this low influence is probably from question indicators that mention mutual or virtual friends of fans on Twitter. Many respondents chose low answers resulting in a disapproval assessment of the question items in the fear of missing out phenomenon variables such as fear of losing mutual, fear of better mutual experiences, fear of mutual getting the opportunity to interact with idols, being left behind in mutual hype, not wanting to miss the moment with each other, and others. K-Pop fans tend to experience FoMO only to their idols, not fandom friends considering the high answer question for the FoMO phenomenon is when the question mentions their idol.

So basically, a fan who has the characteristics of fanaticism requires a high need for information and media content related to his idol and to fulfill this need, causing fans to continue to try to be active on Twitter social media so as not to miss any content. This has led to a tendency for fans to become addicted to social media which at the same time can lead to exposure to the phenomenon of fear of missing out in a K-Pop fan.

\section{CONCLUSION}

According to the results of research, it can be concluded that the degree of closeness or the level of relationship between the variable level of fanaticism of K-Pop fans on Twitter and the phenomenon of fear of 
missing out is in the category of moderate relationship. This can be seen from the calculation results of the correlation value between the variables of the level of fanaticism of K-Pop fans of 0.590 which is in the range $0.40-0.599$ and means that it is in the category of moderate relationship. Meanwhile, the level of fanaticism of K-Pop fans on Twitter affects the phenomenon of fear of missing out, which is known to be low at $0.348(34.8 \%)$. While the remaining $65.2 \%$ are other factors not examined in this study.

\section{ACKNOWLEDGMENTS}

The researchers expresses their deepest gratitude to all parties who have contributed a lot in providing prayers, assistance and encouragement to the author, especially the Department of Communication Studies at Faculty of Social and Political Studies, Lampung University, and previous authors who helped provide information for this research.

\section{REFERENCES}

[1] S. Ayu Pertiwi, "Konformitas dan Fanatisme pada Remaja Korean Wave," Psikohumaniora: Jurnal Penelitian Psikologi, vol. 1, no. 2, pp. 84-90, 2013.

[2] Chung, Farrelly, Beverland and Quester, Exploring Consumer Fanaticism: Extraordinary Devotion in the Consumption Context, 2008.

[3] J. Eliani, M. S. Yuniardi and A. N. Masturah, "Fanatisme dan perilaku agresif verbal di media sosial pada penggemar idola K-Pop," Psikohumaniora: Jurnal Penelitian Psikologi, vol. 3, no. 1, pp. 59-72, 2018.

[4] A. Nuralin, Pengaruh Tingkat Fanatisme Fans KPop Terhadap Perilaku Selective Exposure, 2020

[5] T. Julianingsih, Hubungan Antara Locus of Control dan Fear of Missing Out dengan Kecenderungan Kecanduan Internet pada Penggemar Korean Wave, 2019.

[6] J. Al-Menayes, The Fear of Missing out Scale: Validation of the Arabic Version and Correlation with Social Media Addiction, 2016.

[7] G. Fuschillo, "Fans, fandoms, or fanaticism?," Journal of Consumer Culture, 2018.

[8] J. Jenson, Fandom as pathology: The consequences of characterization, London \& New York:
Routledge, 1992.

[9] Thorne, Bruner, An Exploratory Investigation of the Characteristics of the Consumer Fanaticism, Qualitative Market Reseach, vol.9, no.1, pp.51-72, 2006.

[10] K. Marimaa, THE MANY FACES OF FANATICSM, 2011.

[11] J. Jenson, Fandom as pathology: The consequences of characterization, 1992.

[12] Jung, Shim, Social distribution: K-pop fan practices in Indonesia and the 'Gangnam Style' phenomenon, International Journal of Cultural Studies, vol.17, no.5, pp. 485-501, 2013.

[13] N. Otmazgin and I. Lyan, Hallyu across the Desert: K-Pop Fandom in Israel and Palestine, 2013.

[14] A. Windah, New Social Media and Public Relations: Review of the Medium Theory, 2012.

[15] F. Tresnawati, Hubungan Antara The Big Five Personality Traits dengan Fear of Missing Out About Social Media Pada Mahasiswa, 2016. 